$$
\text { DOE } / \text { PC/ } 89764--75
$$

DEC 2 \& 31991

"Permeability Changes in Coal Resulting from Gas Desorption"

8th Quarterly Report:

$\mathrm{DOE} / \mathrm{PC} / 89764--\mathrm{T} 5$

$7 / 1 / 91-9 / 30 / 91$

DE92 007925

\title{
DISSEMINATION OF RESULTS OF STUDY:
}

During the past year, 4 presentations at scientific meeting have included discussion of data relating to this study:

Levine, J.R., 1990, Quantitative estimation of volatile yields from coal released during organic maturation: American Chemical Society, Division of Geochemistry Preprints, Proceedings of 199th ACS National Meeting, Boston, MA, Abst. \#28.

Levine, J.R., Thompson, D.A., and Telle, W.R., 1990, Coalbed gas resources of Upper Pottsville Fm. near Duncanville, AL: Geol. Soc. of America Abstracts with Programs, v. 22, p. 23.

Tang Y. and Levine, J.R., 1990, Secondary pores in coal: their formation and relationship to coal macerals, Pingdingshan-Jiaosuo coal fields, China: Proceedings, 7th Annual Meeting of The Society for Organic Petrology, Calgary, Alberta, Sept. 8-14, 1990.

Levine, J.R., 1991, Compositional controls on natural gas yields from selected Fruitland coals, San Juan basin, Colorado: Canadian Society of Petroleum Geologists, Programme and Abstracts, 1991 CSPG Convention, June 16-19, 1991, Calgary, Alberta, Canada, p. 93.

In addition, presentation of results was made at DOE contractors meeting in Pittsburgh on June 26, 1991.

Graduate student G. Prakash successfully defended Masters thesis, prepared in partial fulfillment of requirements for degree of Master of Science in Minerals Engineering, University of $\mathrm{A}$ labama. Thesis is entitled:

\section{MAJOR ACCOMPLISHMENTS: SORPTION MICROBALANCE EXPERIMENTS}

(please see attached report)

\section{DISCLAIMER}

This report was prepared as an account of work sponsored by an agency of the United States Government. Neither the United States Government nor any agency thereof, nor any of their employees, makes any warranty, express or implied, or assumes any legal liability or responsibility for the accuracy, completeness, or usefulness of any information, apparatus, product, or process disclosed, or represents that its use would not infringe privately owned rights. Reference herein to any specific commercial product, process, or service by trade name, trademark, manufacturer, or otherwise does not necessarily constitute or imply its endorsement, recommendation, or favoring by the United States Government or any agency thereof. The views and opinions of authors expressed herein do not necessarily state or reflect those of the United States Government or any agency thereof. 


\section{Description of the Experimental Apparatus}

One of the main tasks

was designing and building the experimental apparatus. The set up consisted of the following elements:

1) a high pressure chamber,

2) a CAHN C2000 microbalance,

3) the balance control unit,

4) chart recorder,

5) pressure regulators,

6) digital pressure gauges, and

7) resistance temperature detector (RTD),

The high pressure chamber was tested to $1200 \mathrm{psi}$. The chamber had two outlets at the bottom, one for the sample pan and the other has a Conax fitting for the wires of the balance connecting it to the recorder. The flange of the high pressure chamber had two ports. The one used as the inlet has a baffle on the inside to avoid a direct force on the balance due to the entering gas jet. The other port is used as the gas outlet port (Figure 6). 


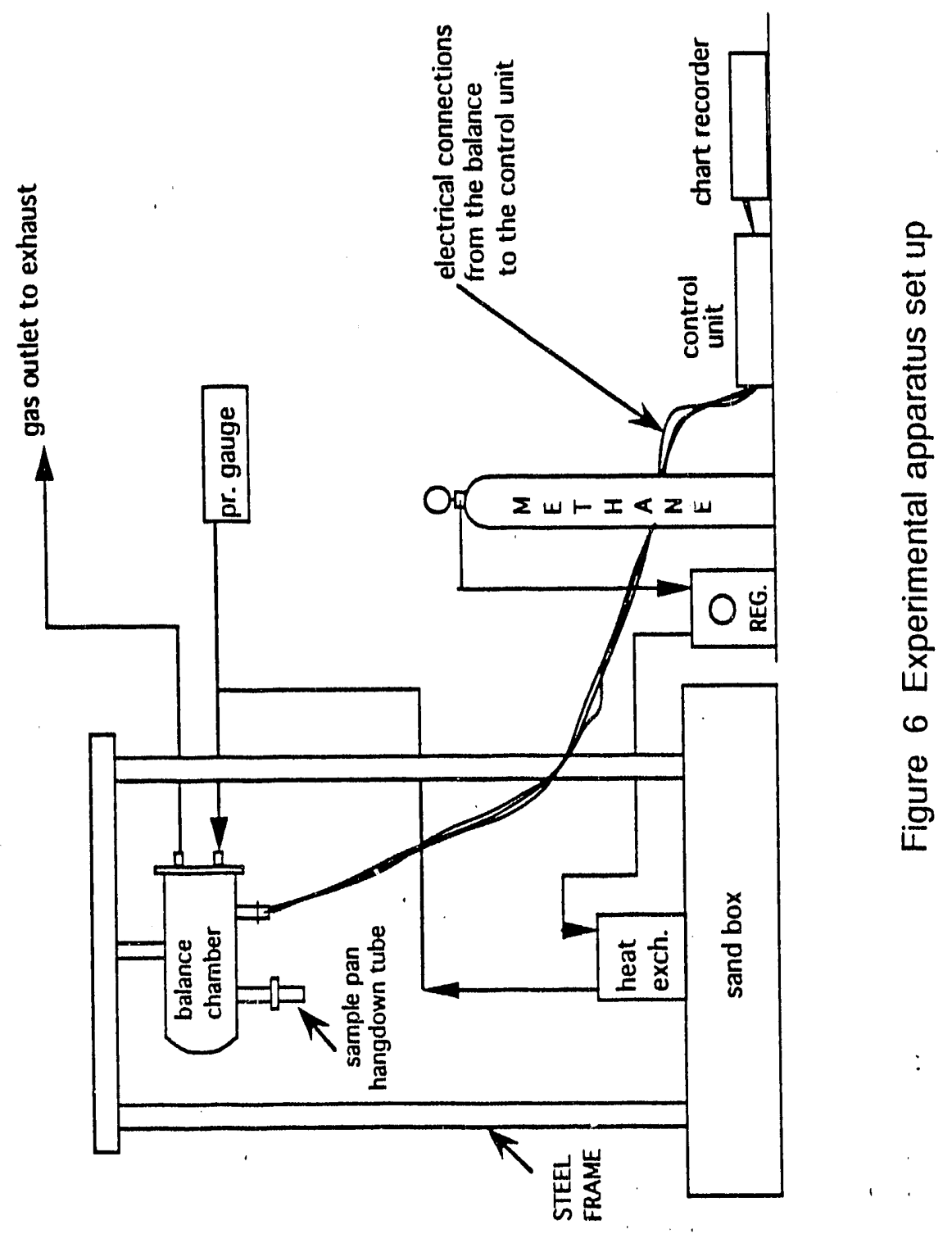




\section{The Microbalance}

The CAHN C2000 model is a very sensitive electromicrobalance. It is designed for weights and forces up to $3.5 \mathrm{~g}$ and small changes in weight up to 0.1 micrograms. The CAHN C2000 instruction manual = describes the balance as a force-to-current converter. The balance beam has 3 fine metal loops ( $A, B$ and tare) attached to it. The sample loop and the tare loop has a maximum capacity of 1.5 grams and the $B$ loop has a capacity of 3.5 grams. Depending on the A or B sample loop chosen to hang the sample pan, the recorder range is selected on the control unit. The output range was selected from the two available ranges of 10 millivolt and 1 millivolt.

\section{The Control Unit}

The 62000 control unit has a 2 step filter, recorder range selection, and suppression range and zero suppression which must be adjusted for each experiment. Deperiding on the accuracy required the RR can be chosen. The RR chosen for the experiment was 1 milligram. The zero suppression helps in extending the range chosen. The 2 step filter provides "noise" reduction on the readout. It filters out electrical and external vibrations at the output to the readout resulting in a stable plot on the chart recorder.

A Linear 1200 model chart recorder with variable chart speed ranging from $1 \mathrm{~cm} / \mathrm{min}$ to $1 \mathrm{~cm} / \mathrm{hr}$ was used. A Bacharach model $\mathrm{CD} 100 \mathrm{~W}$ gas detector alarm was installed close to the chamber as explosive gases 
like methane at high pressures were being used.

The temperature differences were suspected to be dominant inside the balance chamber. To check if this was authentic, it was decided to install two resistance ternperature detectors (RTD's) inside the chamber. An RTD operates on the principle of change in electrical resistance in wire as a function of temperature. The :ype of RTD used is an Omegafilm Platinum resistance temperature detector. Two RTD's were installed inside the chamber, one near the gas inlet port and the other near the sample pan. The RTD's were calibrated aiter being installed in the chamber using an ice and water bath at $0^{\circ} \mathrm{C}$. The temperatures were racorded during the experiments.

The C2000 balance must be zeroed initially. To measure the absolute weight of the sample the weighing unit is calibrated by adjusting the output to "0" with no sample on the pan. The balance is calibrated using a $100 \mathrm{mg}$ calibration weight on the sample pan. It is important to note that the CAHN C2000 is not an equal arm balance, i.e. the sample pan loop and the tare pan loop are not equidistant from the fulcrum. Hence using it to determine weights on the sample pan by using tare weights on the tare pan will yield a $1 \%$ error in the results. It is designed primarily to measure changes in weight rather than the absolute weight.

\section{Problems faced in setting up the experiment}

Initially the high pressure chamber with the microbalance installed inside was placed in a thermally insulated box. The beam inside the thermal box was found to be saggirig due to the weight of the high 
pressure chamber. Hence the microbalance could not be kept in a horizontal position inside the chamber. Also the chart recorder was indicating considerable noise in the recording. A sturdy steel frame was fabricated to keep the pressure chamber fastened in a horizontal position.

The microbalance was installed inside the high pressure chamber and was positioned horizontally with a spirit level. The electrical wiring from the balance to the control unit which passes through a Conax high pressure fitting had to be done twice. First time, due to insufficient insulation, shorting was observed in the wires and then in the second time the wire was short in length and could not be connected to the control unit due to the repositioning of the control unit.

Once installed, the balance was checked for proper functioning. The chart recorder plot was found to be 'noisy' (continuous wide swings in the readings). The noise was attributed to the building vibrations. To suppress this noise a six-inch deep, fine sand cushion was provided below the steel frame. The sand was able to absorb the vibrations and the chart recorder gave a steady output.

The balance was then zeroed as per the CAHN C2000 instruction manual and it was found that the recorder zero suppression (RZS) was not working precisely. The circuit was checked and a faulty capacitor was replaced to set it right. After the zeroing of the balance was done, the pressure chamber was sealed and pressure tested to 1100 psig with nitrogen and helium. A number of leaks were detected using 'snoop' and soap solutions in the various fittings and the connections used. These leaks were rectified and the chamber was pressure tested to $1100 \mathrm{psig}$. 


\section{Theory and Experiments Conducted}

\section{Theory}

The microbalance installed in a high pressure chamber was used to measure the weight changes due to gas sorption at increasing pressure steps from 0 to $1000 \mathrm{psig}$. The complete step by step procedure is available in the appendix. The weight chariges measured with the microbalance were recorded on a chart recorder. The raw weight changes recorded during the experiments had to be corrected for buoyancy and sample swelling. As the pressure in the balance chamber increases, the buoyancy forces tend to increase. The data were corrected and examined on the basis of five different sets of assumptions. At high pressures gas volumes measured have to be corrected for compressibility. Hence the Z-factor correction was applied to all the calculations involved. The assumptions and the recordings as seen on the chart paper of the recorder is shown in the figure

The experimental data was analysed using the five cases. The different cases were developed with certain assumptions. The five cases and the equations involved in each of them are discussed here. 


\section{Case 1}

The assumptions for case 1 :

a) the volume of coal sample is constant (no swelling of the sample occurs;

b) the weight change is entirely due to sorption; and

c) that no sorption occurs during the time the pressure is being changed.

Hence

$$
W_{i, 2}-W_{i, 1}=\Delta W_{i}=\Delta V_{g i} \rho_{g 0}
$$

where $\Delta \mathrm{V}_{\mathrm{gi}}$ is the volume of gas sorbed, and $\rho_{\mathrm{go}}$ is the density of methane at STP.

$$
\begin{gathered}
\Delta \mathrm{V}_{\mathrm{g}_{1}}=\frac{\Delta \mathrm{W}_{\mathrm{i}}}{\boldsymbol{P}_{\mathrm{g}_{0}}} \\
\mathrm{~V}_{\mathrm{g}}=\sum_{\mathrm{i}} \Delta \mathrm{V}_{\mathrm{g}_{1}}
\end{gathered}
$$

where

$$
\rho_{\mathrm{g}(\text { methane })}=\frac{16 \mathrm{~g}}{\mathrm{~g} \text { mole }} * \frac{\text { gmole }}{22.41} * \frac{1}{1000 \mathrm{cc}}=0.000714 \frac{\mathrm{g}}{\mathrm{cc}}
$$

at STP.

\section{Case 2}

In this case the volume of sorbed gas is calculated from the measured 


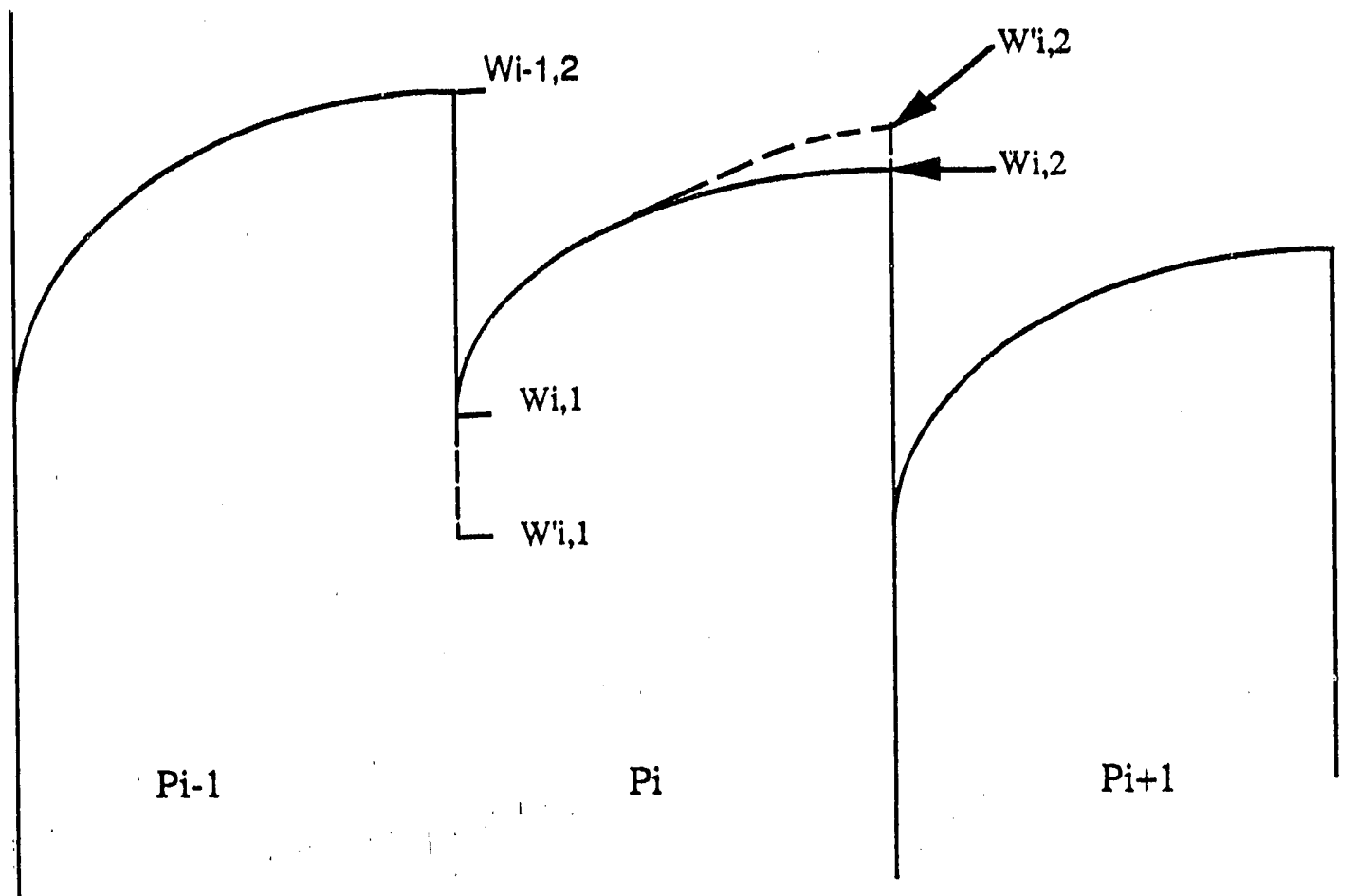

Wi-1,2 : Measured weight after sorption pressure $\mathrm{Pi}-1$

Wi,1 : Measured weight

$W^{\prime \prime} 1,1$ : Calculated from Wi-1,2 or W'i-1,2 and the cumulative volume related buoyansy

Wi,2 : measured weight after sorption equilibrium.

$W^{\prime} i, 2$ : Corrected for buoyancy changes due to volume swelling

P : Pressure

i : step

Figure 7 Chart Recorder sample output 
weight change occurring due to the change in pressure from $P_{i}$ to $P_{i+1}$. The buoyancy correction is calculated from the volume and density of the sorbing gas. The compressibility corrections (Z-factor) are applied to the gas density. This case also assumes that there is no sorption taking place during the time the gas is being admitted into the chamber to increase the pressure.

Hence the mass balance equation across the sample is

$$
\begin{aligned}
& \Delta \mathrm{W}_{\mathrm{i}}=\mathrm{V}_{\mathrm{ci}-1}\left(\rho_{\mathrm{ci}-1}-\rho_{\mathrm{gi}}\right)+\Delta \mathrm{V}_{\mathrm{ci}}\left(\rho_{\mathrm{di}}-\rho_{\mathrm{gi}}\right)-\mathrm{V}_{\mathrm{ci}-1}\left(\rho_{\mathrm{ci}-1}-\rho_{\mathrm{gi}}\right) \\
& \frac{\Delta \mathrm{W}_{\mathrm{i}}}{\Delta \mathrm{V}_{\mathrm{ci}}}+\rho_{\mathrm{gi}}=\rho_{\mathrm{di}}=\frac{\Delta \mathrm{W}_{\mathrm{di}}}{\Delta \mathrm{V}_{\mathrm{ci}}} \\
& \therefore \mathrm{W}_{\mathrm{di}}=\Delta \mathrm{W}_{\mathrm{i}}+\Delta \mathrm{V}_{\mathrm{ci}} \rho_{\mathrm{gi}}
\end{aligned}
$$

where

$$
\begin{array}{ll}
\Delta \mathrm{W} & =\text { weight change measured in } \mathrm{mg} \\
\mathrm{V}_{\mathrm{C}} & =\text { volume of coal }(\mathrm{cc}) \\
\rho_{\mathrm{c}} & =\text { density of coal }(\mathrm{g} / \mathrm{cc}) \\
\rho_{\mathrm{g}} & =\text { density of sorbing gas }(\mathrm{g} / \mathrm{cc}) \\
& =\text { initial measurement } \\
n & =\text { final measurement } \\
\mathrm{d} & =\text { deposited } \\
\Delta \mathrm{W}_{\mathrm{d}} & =\text { actual weight of sample after buoyancy correction. }
\end{array}
$$

Taking a mass balance, to determine the coal volume $V_{C l}$ the equation is 


$$
\begin{aligned}
W_{i+1,1}-W_{i, 2} & =V_{c i}\left(\rho_{c i}-\rho_{g i+1}\right)-V_{c i}\left(\rho_{c i}-\rho_{g i}\right)+\Delta W_{p i} \\
& =V_{c i}\left(\rho_{g i}-\rho_{g i+1}\right)+\Delta W_{p i} \\
\therefore V_{c i} & =\left(\frac{1}{\rho_{g i}-\rho_{g i+1}}\right)\left(W_{i+1,1}-W_{i, 2}-\Delta W_{p i}\right)
\end{aligned}
$$

\section{Case 3}

In case 3 the assumptions are that the sample volume increases due to adsorbed methane and there is no sorption during pressure change.

$$
W_{d i}=\Delta W_{i}+\Delta V_{\text {di }} P_{g i}
$$

but

$$
\Delta \mathrm{V}_{\mathrm{ci}}=\frac{\mathrm{W}_{\mathrm{di}}}{\rho_{\mathrm{d}}}
$$

The value of $\rho_{d}$ is obtained from the reference

$$
\rho_{d}=0.636 \mathrm{~g} / \mathrm{cc}
$$

$$
\begin{aligned}
& W_{d i}=\Delta W_{i}+W_{d i}\left(\frac{\rho_{g i}}{\rho_{d}}\right) \\
& W_{d i}=\Delta W_{i} /\left(1-\frac{\rho_{g i}}{\rho_{d}}\right)
\end{aligned}
$$

\section{Case 4}

The assumptions for this case are that the sample volume increases due 
to deposited methane with a density of $0.636 \mathrm{~g} / \mathrm{cc}$, sorption is occurring during the pressure change and the weight is calculated from buoyancy correction. The sample volume is calculated from the following equation:

$$
\mathrm{V}_{\mathrm{cn}}=\mathrm{V}_{\mathrm{c} 0}+\sum_{\mathrm{i}}^{\mathrm{n}} \Delta \mathrm{V}_{\mathrm{ci}}
$$

where

$$
v_{c 0}=\frac{W_{i}}{1000 * \rho_{c}}
$$

$\rho_{c}$, the density of coal is $1.4 \mathrm{~g} / \mathrm{cc}$ from the density calculated using a pycnometer:

The final weight of the sample is given as:

$$
W_{n, 1}^{\prime}=W_{n-1,2}-V_{c n}\left(\rho_{g n}-\rho_{g n-1}\right)+\Delta W_{p n}
$$

where $\Delta \mathrm{W}_{\mathrm{p}_{\mathrm{n}}}=$ change in the weight of sample pan with change in pressure.

The weight of the pan measured during buoyancy calibration is used to calculate the buoyancy force. This case is the best and involves all possible corrections and as compared to the others, it is the most reliable one.

\section{Case 5}

In this case the coal volume is assumed to be constant and the weight is 
calculated from buoyancy correction.

$$
\begin{aligned}
& \mathrm{V}_{\mathrm{cn}}=\mathrm{V}_{\mathrm{co}} \\
& \mathrm{W}_{\mathrm{n}, 1}^{\prime}=\mathrm{W}_{\mathrm{n}-1,2}-\mathrm{V}_{\mathrm{c} 0}\left(\rho_{\mathrm{gn}}-\rho_{\mathrm{gn}-1}\right)+\Delta \mathrm{W}_{\mathrm{pn}}
\end{aligned}
$$

The sorption values were calculated and the plots made indicate the sorption capacities of different types of coals at various pressures.

In order to represent the various coals as regards to the range of compositions samples were obtained from two basins namely, Illinois Basin and Black Warrior Basin, Alabama. The Black Warrior Basin coal ranges in rank from high volatile $A$ bituminous to low volatile bituminous. The samples were taken from active mines and were of the following types:

a) Low ranked sample with the anticipation of high surface area, and

b) High ranked coal with the anticipation of lower surface area.

The samples were obtained in the form of blocks and ground in a grinder in the lab and sieved to the specific particle sizes. The experiment was conducted using two particle size of samples separately : 20 mesh and 60 mesh. Proximate, ultimate, and BTU analyses were conducted at the UA Mineral Resources Institute analytical laboratory, according to ASTM standard methods. The analysis results are included in the appendix.

\section{Experiments conducted}

The following experiments were conducted as part of the study:

1) Measurement of buoyancy of the microbalance 
2) Methane sorption studies on Illinois basin coal sample ( 20 and 60 mesh )

3) Sorption measurements of methane on Black Warrior basin, Alabama coal ( 20 and 60 mesh ).

4) Sorption measurements of carbondioxide on Alabama and Illinois coal samples.

1) Measurement of the buoyancy of the microbalance -

Measurement of the buoyancy effects on the pans, the tare weights and the arms of the balance are important as the weight measured needs to be corrected for buoyancy. As measurements were made at high pressures the buoyancy effects became more critical. The buoyancy effects were studied using an empty sample pan. The weight changes were recorded aî pressures of $50 \mathrm{psig}$ and $100 \mathrm{psig}$ and then on at increments of $100 \mathrm{psig}$, up to $1000 \mathrm{psig}$. The weight changes due to decreasing pressure were also recorded when the pressure was reduced in stages from $1000 \mathrm{psig}$ to 0 psig. The exprriment was repeated using methane, carbondioxide and helium. The plot of weight change data vs pressure was made. This plot was used in calculating the buoyancy of the balance in the different gas environments.

2) Methane sorption studies on Illinois Basin coal sample:

The coal sample from the Illinois Basin was crushed,ground and sieved to get a uniform sample of 20 mesh size. The coal sample was left in the balance chamber to degas for a long period under vacuum till the weight of the sample was constant. The weight loss during the evacuation 
is thought to be due to the removal of moisture and any inherent methane. The methane gas sorption experiment was carried out at various pressures. The weight changes were recorded. The sorption of methane was recorded at pressures ranging from 50 to $1100 \mathrm{psig}$. The experiments were repeated for another sample of 60 mesh size and the sorption measurements were recorded.

3) Measurement of methane sorption on Black Warrior basin sample:

The sorption measurements were repeated for the Black Warrior basin sample as done in the case of the Illinois sample.

4) Measurement of carbon dioxide, sorption on Alabama and Illinois coals: Carbon dioxide sorption on the two different types of coals of varying particle sizes were recorded. The sorption isotherms were plotted and a comparison was made to the methane sorption data. 


\section{Results and Analysis}

The data obtained was analysed using the five different cases discussed in the theory section. The buoyancy plots were used in calculating the buoyancy correction. The isotherms generated by the experiment were plotted along with the Langmuir's isotherm. The analysis is further discussed in this chapter in detail.

\section{Buovancy correction plots}

Any weight measurements taken with a balance in a high pressure system requires correction for buoyancy. Experiments were carried out to determine buoyancy corrections using three different gases namely methane, carbon dioxide and helium. The weight changes were recorded on a chart recorder at pressure steps of 100 psig from 0 to 1100 psig. Figures 8 to 10 show the plots of weight changes due to buoyancy in different gases which are approximately linear. It is seen from the plots that buoyancy correction is higher with increase in the molecular weight of the gas. Carbon dioxide showed the maximum buoyancy correction effect and helium the least. 


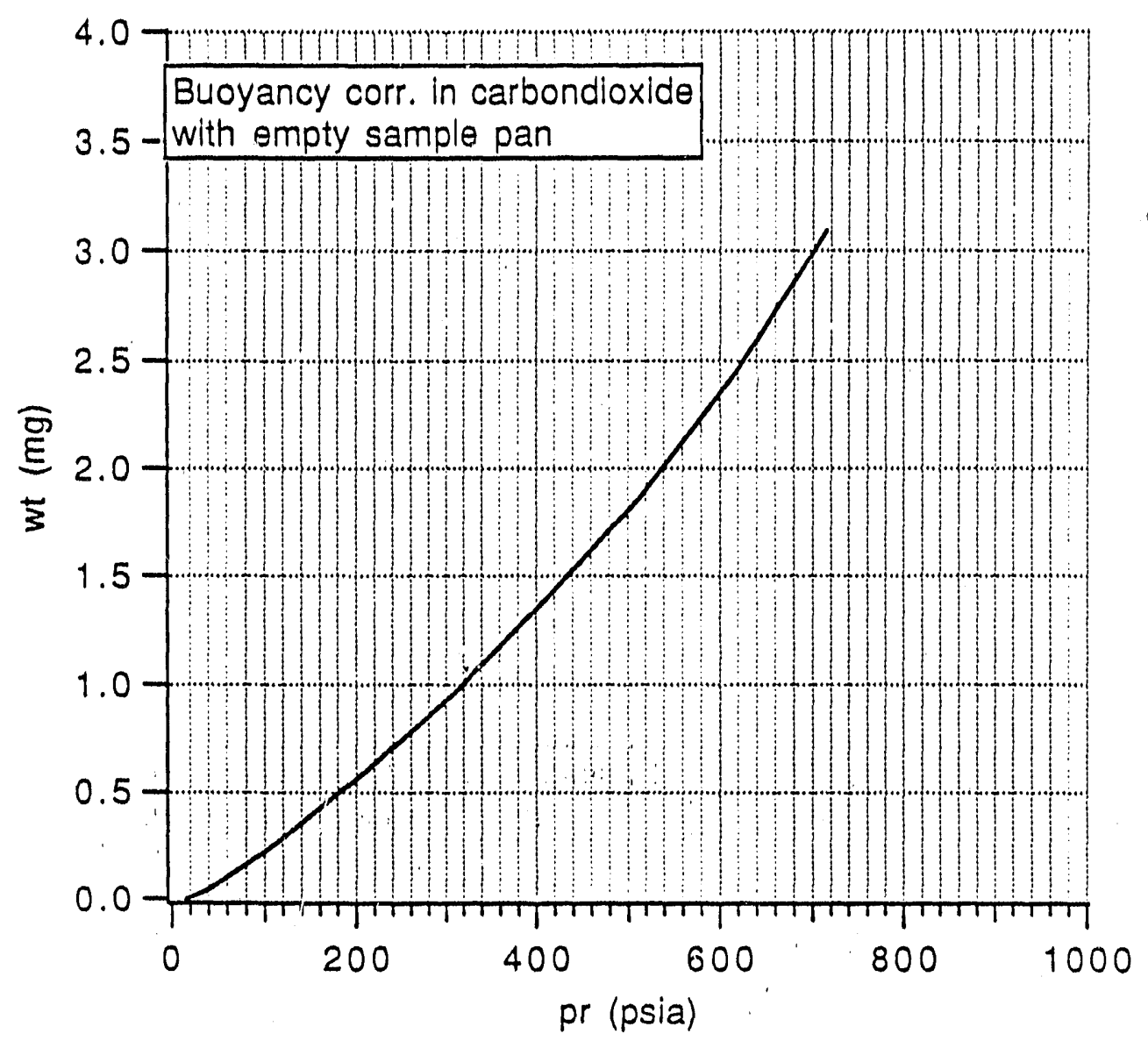

Figure 8 Carbon dioxide buoyancy plot 


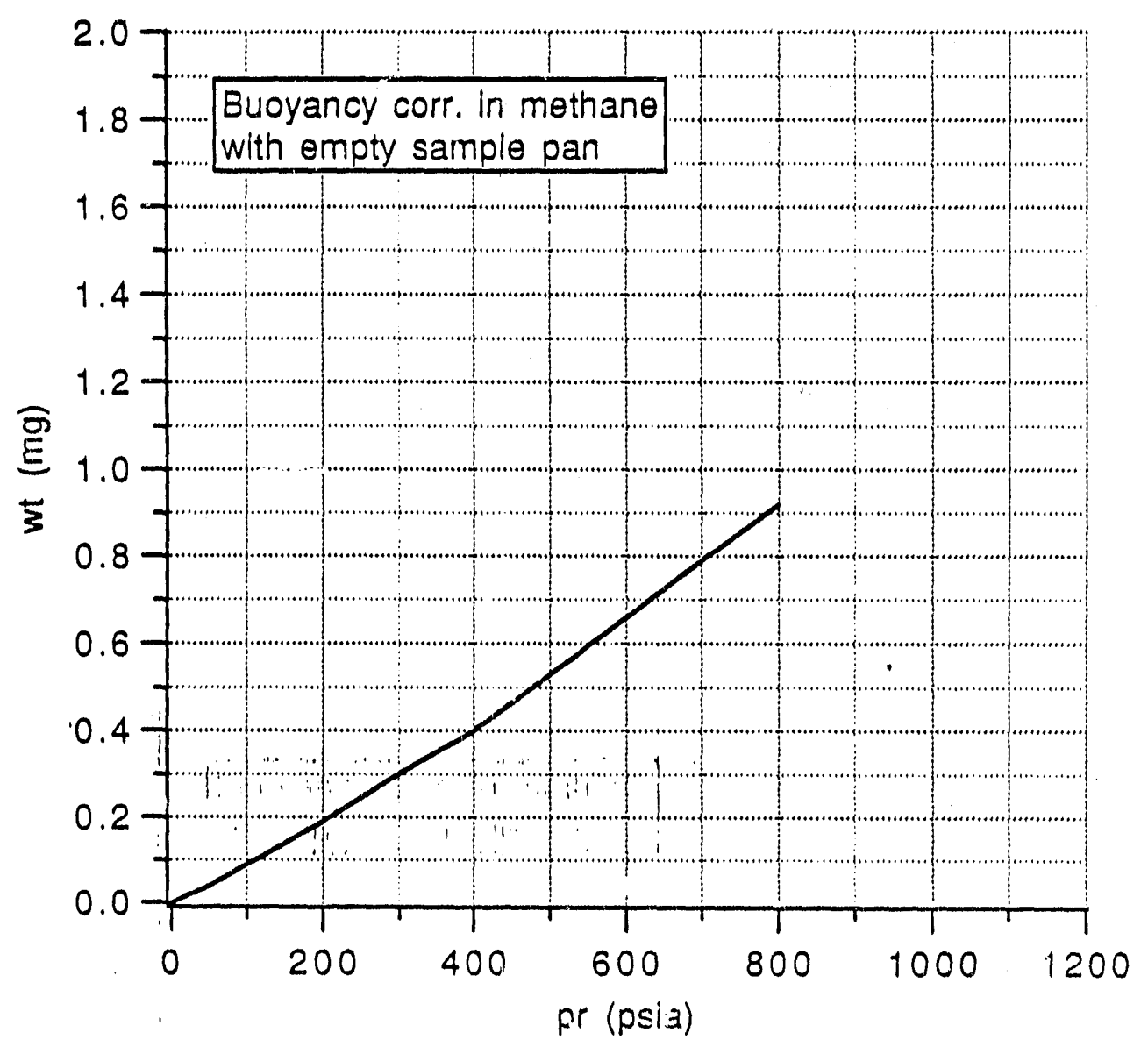

Figure 9 Methane buoyancy plot 


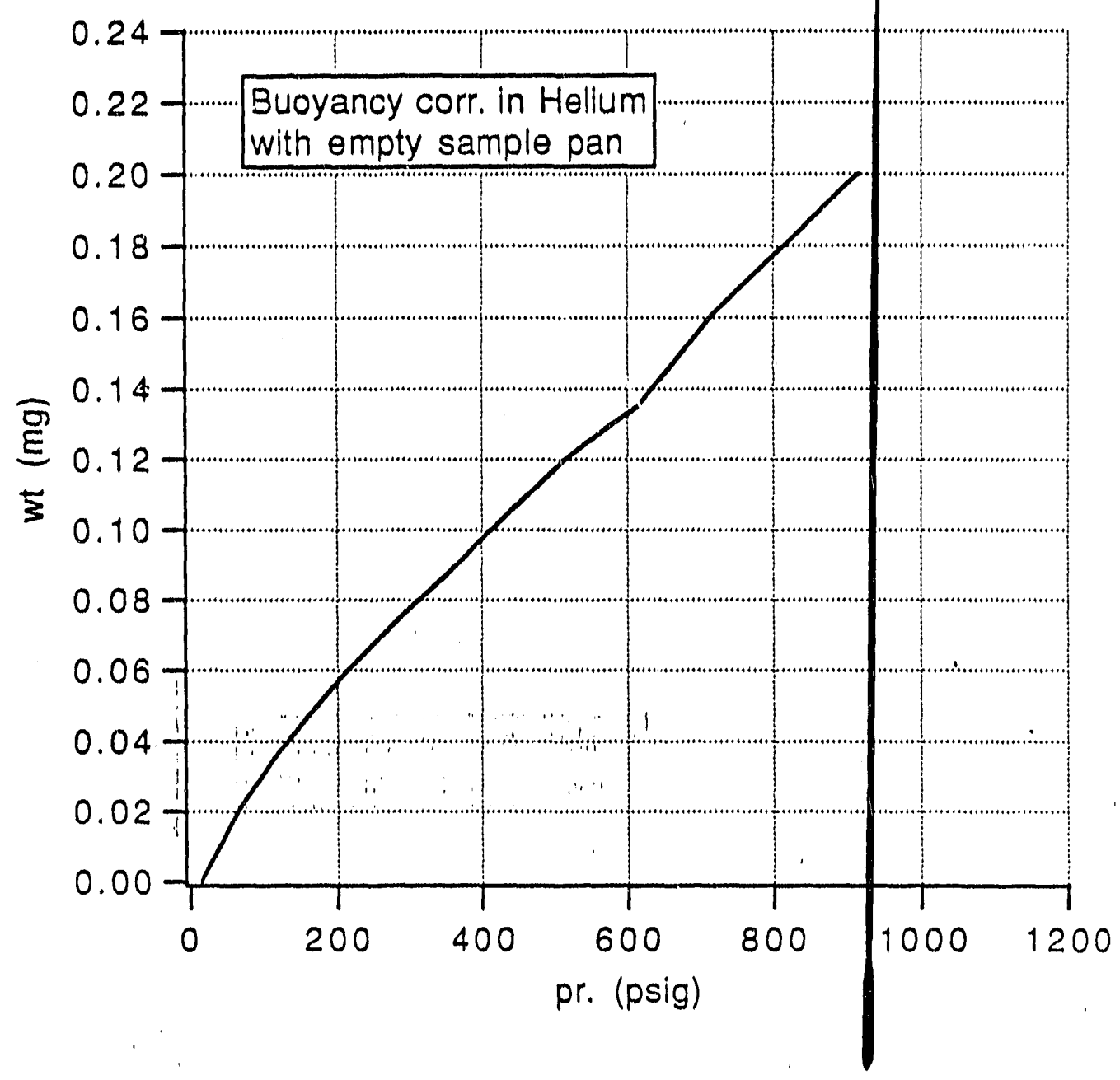

Figure 10 Helium buoyancy plot 


\section{Analysis of sorotion isotherms}

Methane sorption isotherms were plotted for all the four samples ( Al 20, Al 60, IIII 20, IIII 60). The plots according to the five different cases of analysis were made for each sample (figure 11 to 15). The gas sorbed was calculated at standard conditions in milliliters / gram of coal. The analysis of the isotherms for each sample is discussed separately.

\section{Methane sorotion}

Case 1: The volume of the coal and the Initial weight of sample was assumed to be constant. Hence volume swelling and the sorbed volume was not taken into account while calculating the amount of methane sorbed. The isotherm gives lower values of methane content.

Case 2: The volume of coal is calculated from the measured weight changes and so the swelling and sorbed volume is accounted for. However, since sorption can occur very rapidly during the pressure change these measurements were not considered to be trustworthy. The slight deviation at higher pressures beyond 600 psi is not explainable and may be an experimental distortion.

Case 3: The sample volume increases due to deposited methane. This increase in volume $\left(\mathrm{dV}_{\mathrm{C}}\right)$ is calculated as explained in the theory section. As the weight change does not account for sorption occurring while the pressure is being changed to the next higher step, this isotherm indicates 


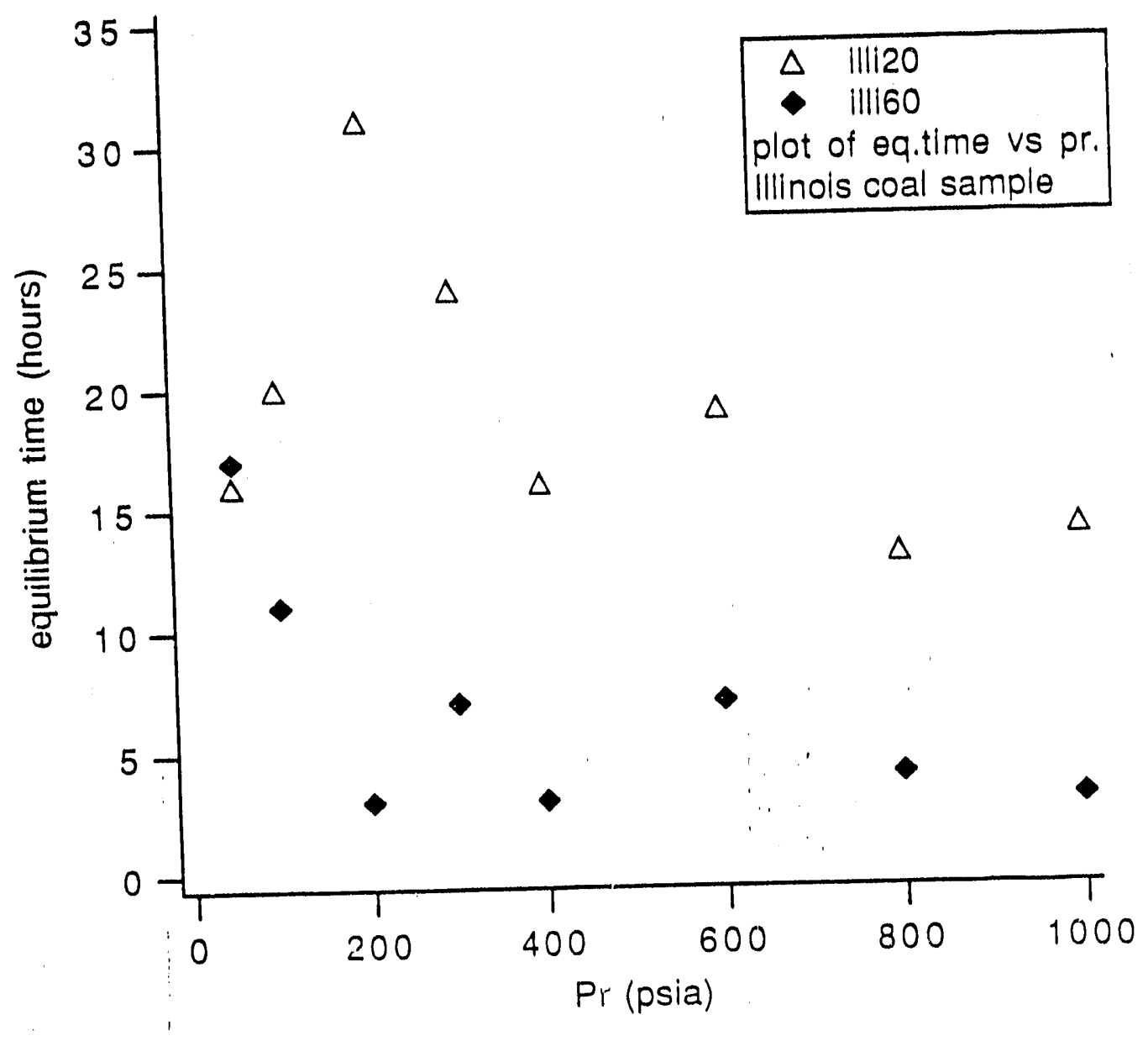

Figure 18 A Time Analysis plot (Illinois coal) 
lower values of gas content.

Case 4: This case is the ideal one as the weight is calculated from buoyancy effects and the volume sweilling and sorption during pressure change are also considered. This isotherm projects more accurate gas content values than the other cases.

Case 5: In this case the sample volume is assumed constant so that the swelling of the sample is not taken into account. The weight is calculated with buoyancy corrections and hence the isotherm matches with the experimental values.

The plot in figure 15 shows a comparison of sorption of methane as per Case 4 for all the four samples studied. The gas content is more in the high ranking Alabama coal than the low ranking Illinois coal. The effect of particle size was not evident upto 400 psi. A: higher pressures the larger mesh size particles showed greater sorption.

\section{Carbon dioxide scrption}

The sorption of carbondioxide on coal was studied on both the types of coal samples. The figures 16 and 17 show the isotherms. The isotherms were plotted for case 2 and case 4 . The sorption isotherms plotted were compared to the methane isoiherms. It was seen that the amount of caroondioxide sorbed was about 2 to 2.3 times the methane sorbed at the higher pressures steps. Ettinger, et. al. 23 observed that the 


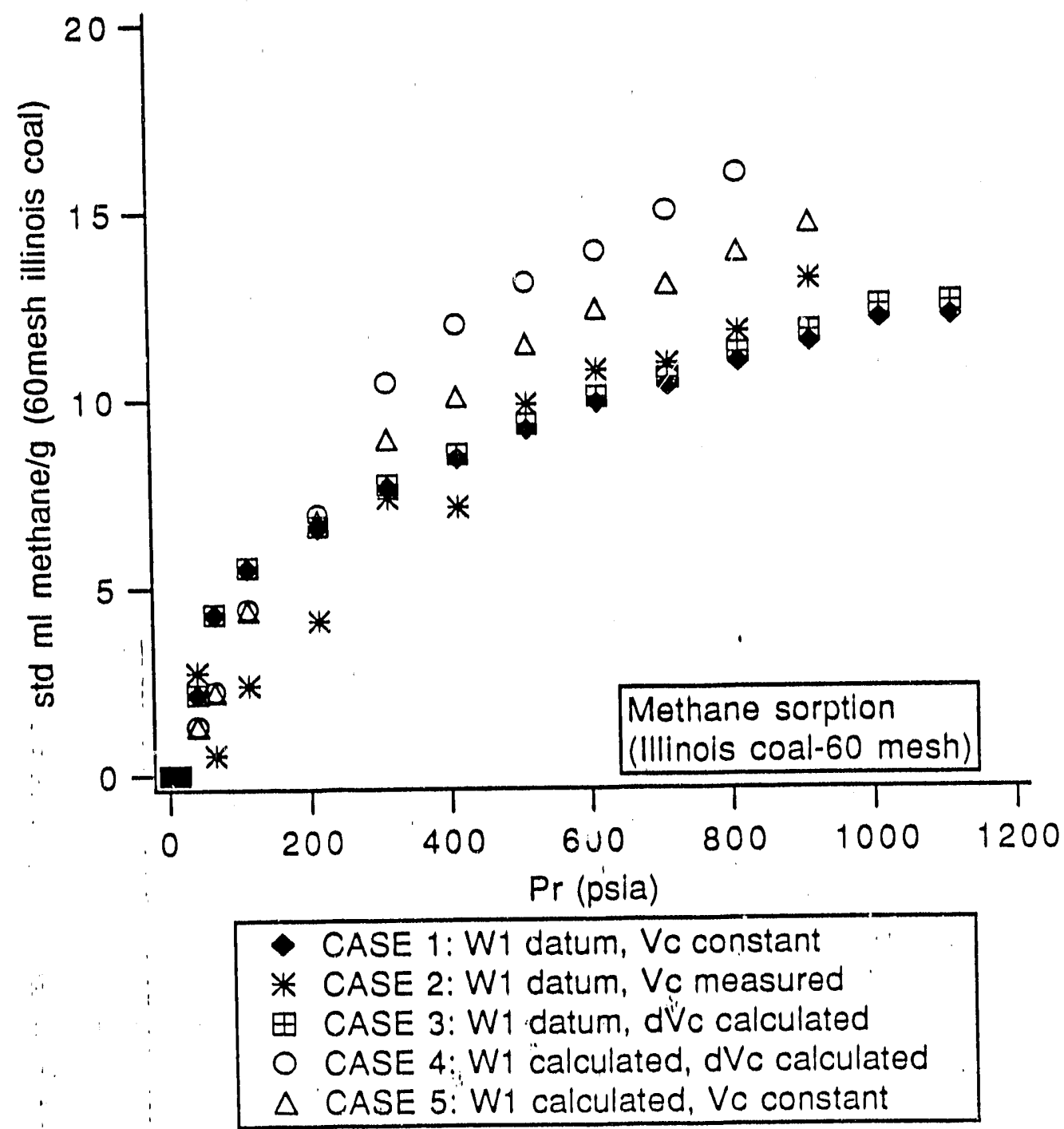

Figure 11 Methane sorption isotherms (Illinois basin coal - 60 mesh) 


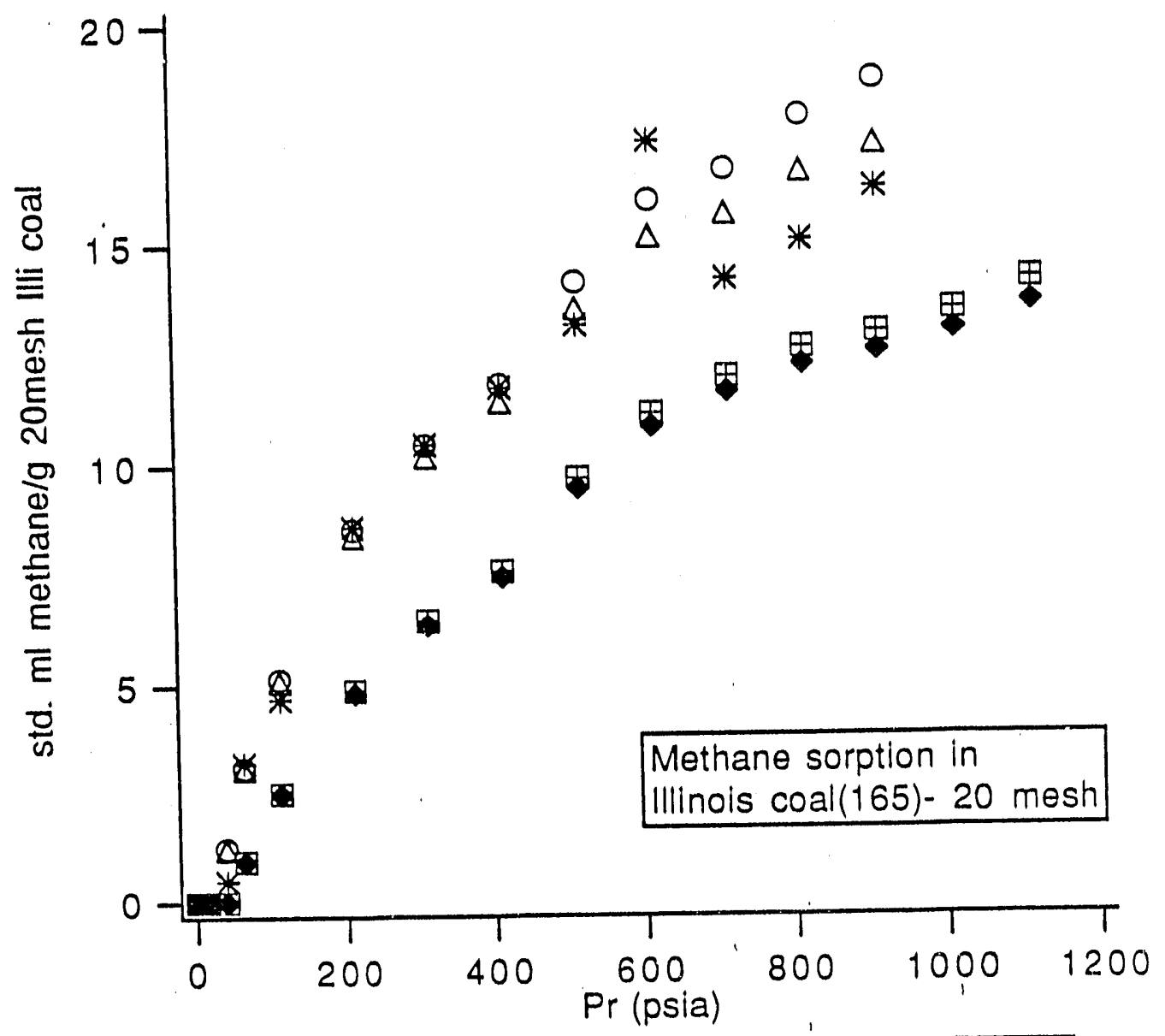

- CASE 1: W1 Datum, Vc constant

* CASE 2: W1 Datum, Vo measured

$\boxplus$ CASE 3: W1 Datum, dVc calculated

- CASE 4: W1 calculated, dVc calculated

$\triangle$ CASE 5: W1 calculated, Vc constant

Figure 12 Methane sorption isctherms (Illinois basin coal-20 mesh) 


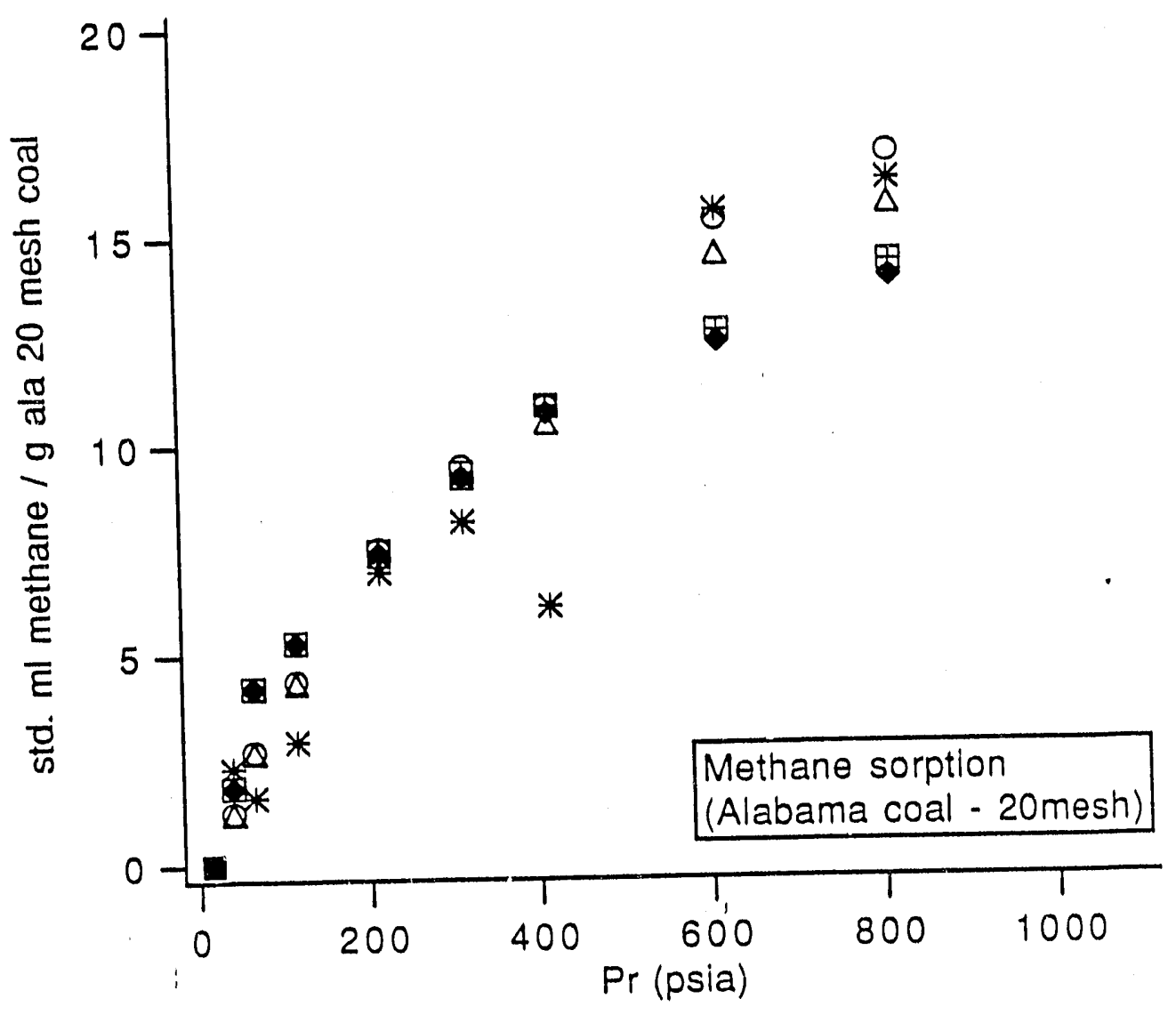

- CASE 1: W1 datum, Vo constant

* CASE 2: W1 datum, Vc measured

$\boxplus$ CASE 3: W1 datum, dVc calculated

- CASE 4: W1 calculated, dVc calculated

$\triangle$ CASE 5: W1 calculated, Vc constant

Figure 13 Methane sorption isotherms (Alabama coal-20 mesh) 


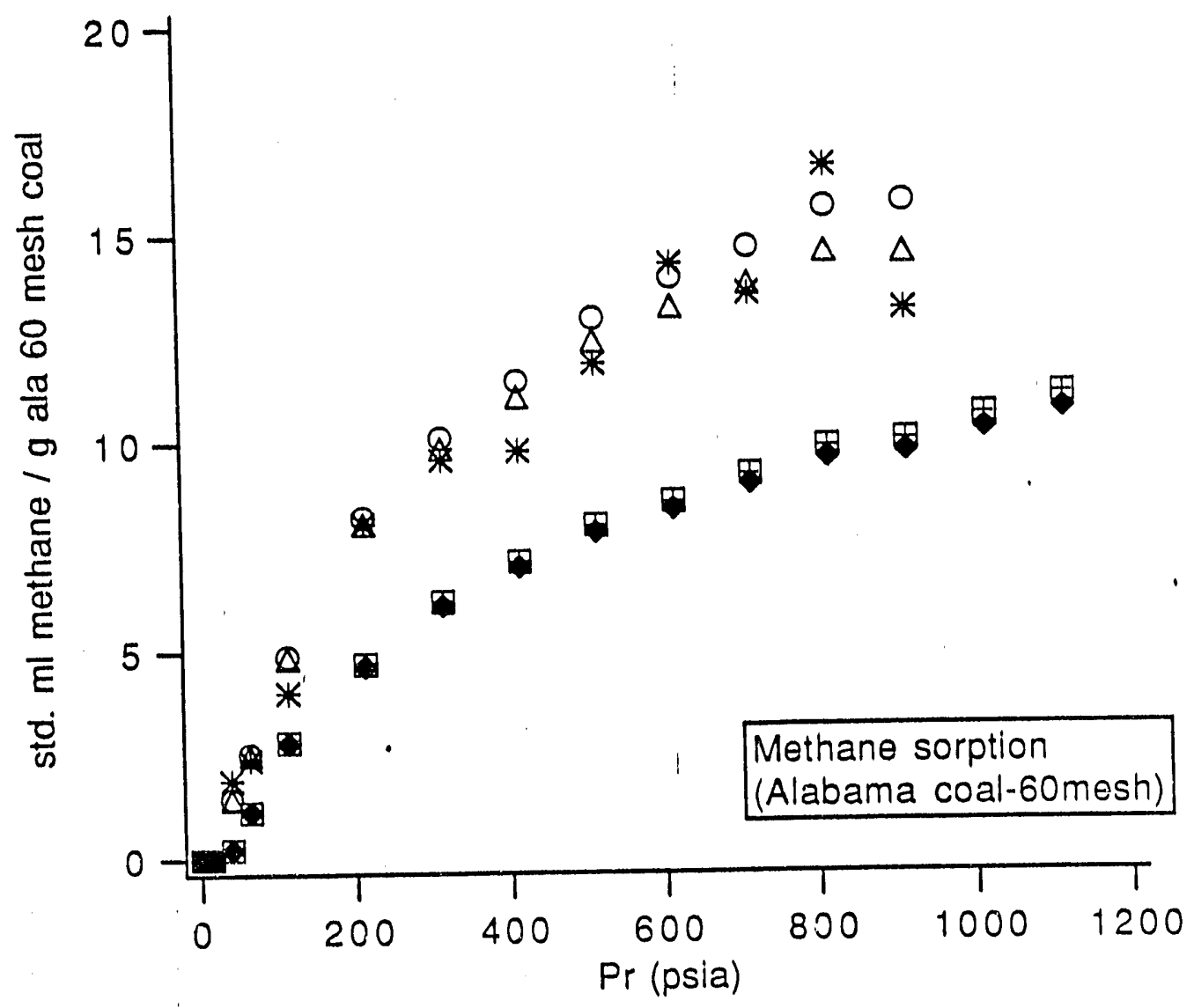

Figure 14 Methane sorption isotherms (Alabama coal-60 mesh) 


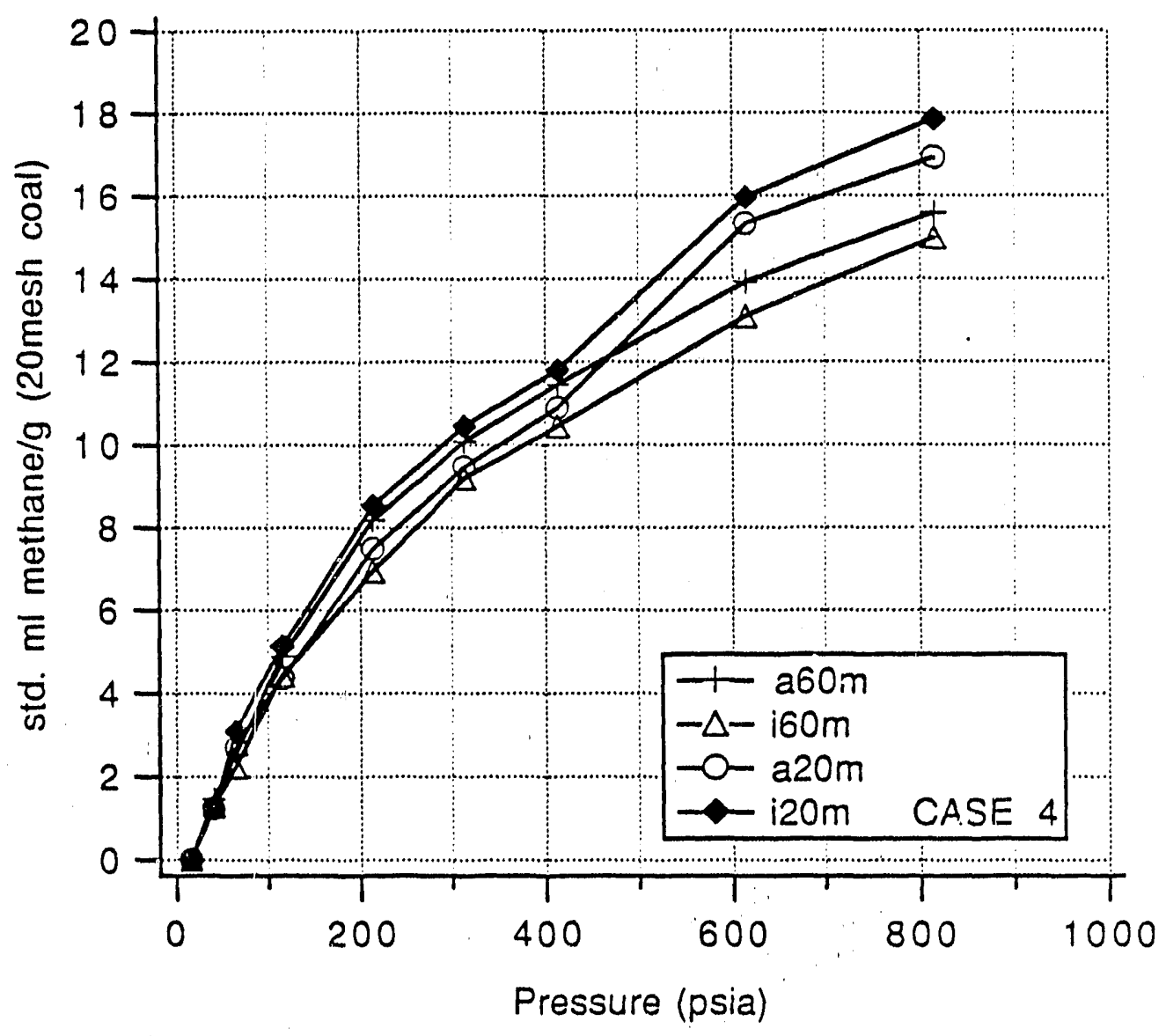

Figure 15 Comparative isotherm plot of the four samples of coals (case 4) 


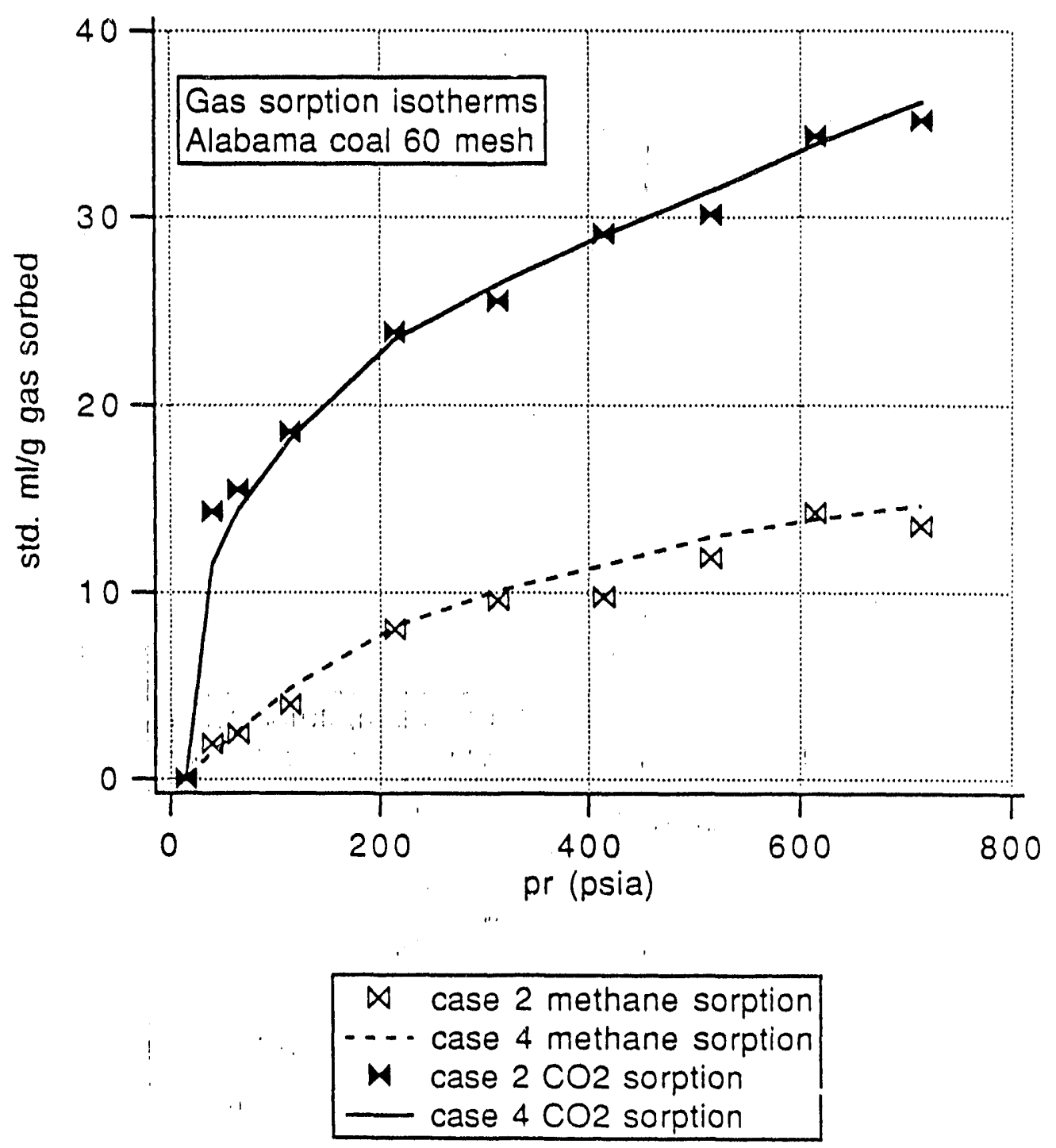

Figure 16 Comparative plot of methane and carbon dioxide sorption (Alabama coal - 60 mesh) 


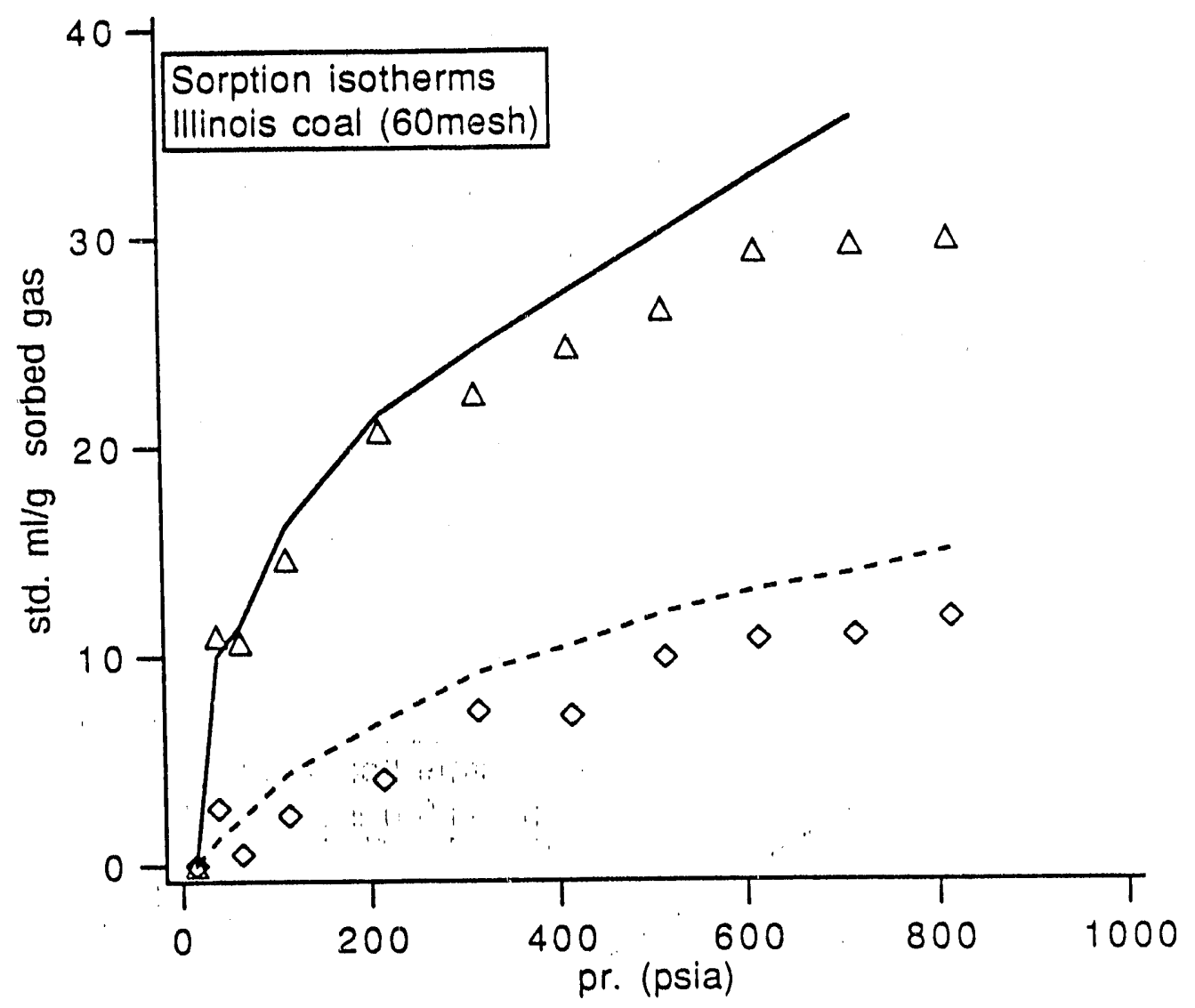

Figure 17 Comparative plot of methane and carbon dioxide sorption (llinois coal - 60 mesh ) 
sorption capacity of coals corresponds to the higher temperature of !quefaction of carbon dioxide $(-78.5 \mathrm{C})$ as compared with methane ($161.5 \mathrm{C})$. The sorption of carbon dioxide increases with coal rank. The high rank Alabama coal showed a higher amount of sorption than the lllinols coal. 
sorption capacity of coals corresponds to the higher temperature of !quefaction of carbon dioxide $(-78.5 \mathrm{C})$ as compared with methane ($161.5 \mathrm{C})$. The sorption of carbon dioxide increases with coal rank. The high rank Alabama coal showed a higher amount of sorption than the lllinols coal. 

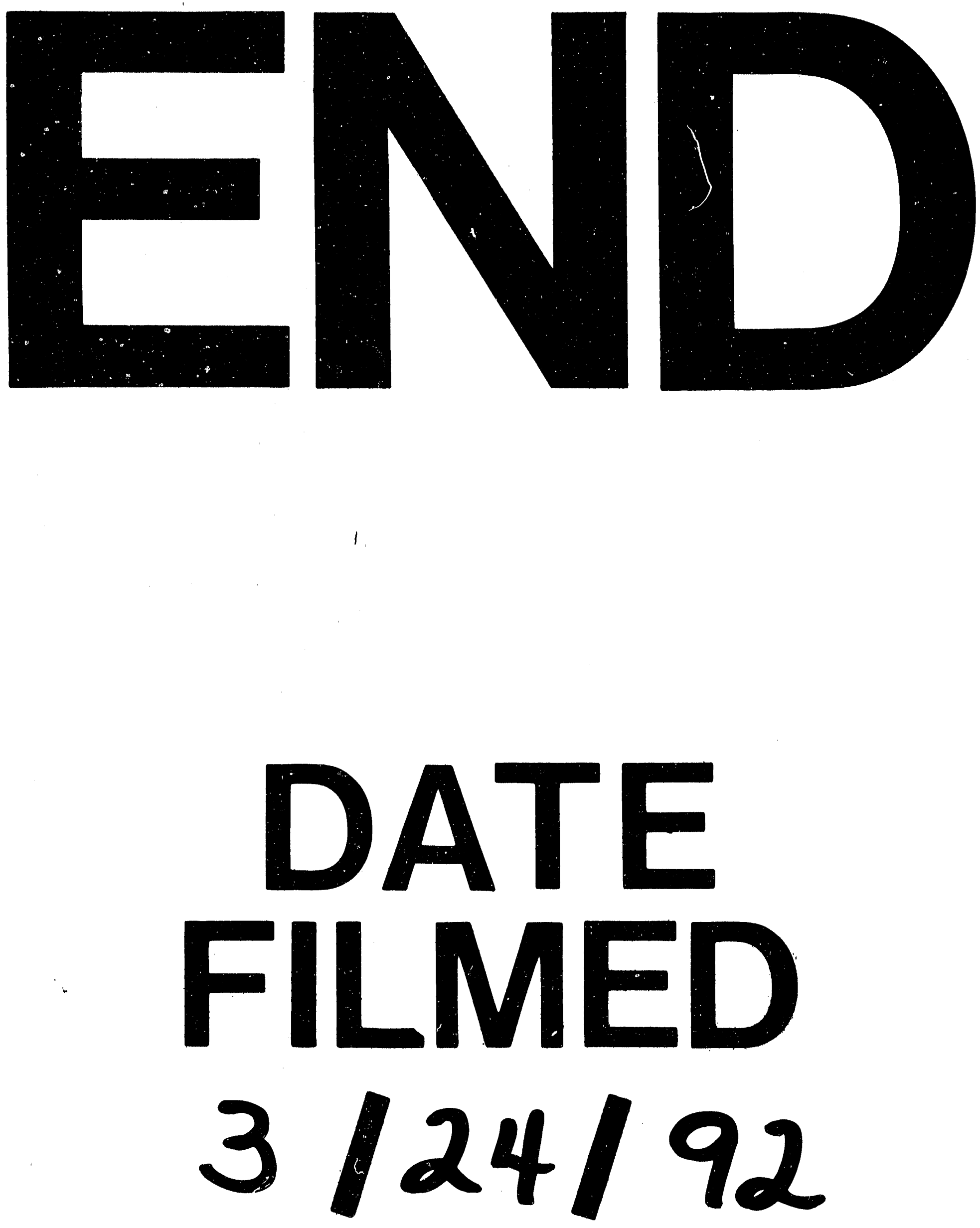